Implantación del Servicio de atención temprana en el Área Rural de Bortziriak

\author{
Implementation of the Early Care Service in the Rural Area of \\ Bortziriak
}

\title{
B. Compains
}

El servicio de atención temprana es un recurso que la administración pone para atender a niños de cero a 6 años con problemas en el desarrollo psicomotor o grave riesgo de padecerlos. Consiste en valorar en el momento de la detección el desarrollo del niño en todos sus aspectos y tratar de estimular a aquellos más retrasados a través de distintos métodos. Además debe atender las necesidades de las familias, asesorándoles para ayudarles a aceptar el problema y a manejarlo. Debe coordinarse con centros escolares para trabajar de forma adecuada con ellos.

El servicio de atención temprana realiza labores de prevención de deficiencias, de tratamiento y de rehabilitación. En estos momentos, las líneas de trabajo no tienen al niño afecto como único protagonista. La familia cobra un papel importante y determinante en muchos casos de la evolución del niño.

En Navarra se oferta este servicio desde hace más de 20 años, pero sólo hace un año se oferta además de en Pamplona en zonas rurales.

Bortziriak es una comunidad de norte de Navarra con 5 pueblos y unos 8.000 habitantes. Ninguno de los niños de esta comunidad había accedido a este servicio hasta que se implantó en la zona.
El centro de salud y la asociación ELAIA, formada por profesionales que trabajamos con niños de la zona, tomamos parte activa en la reivindicación de que este servicio se diera en Bortziriak sin tener que desplazarse a Pamplona.

La aceptación por parte de la administración de ofertar este servicio en áreas rurales, vino acompañado de la elaboración de un Decreto Foral que lo regula.

En resumen, el servicio queda estructurado de la siguiente forma:

- Niños de cero a tres años. El proceso lo lidera el Departamento de Bienestar Social a través del centro base. La detección se realiza en el centro de salud (pediatría), en las escuelas infantiles o en los servicios sociales. Tras la detección, tanto los padres como los profesionales, pueden solicitar al servicio de atención temprana la valoración del niño.

Para realizar esta valoración se desplaza un equipo de profesionales (psicólogo, médico rehabilitador, trabajadora social) del Centro Base al Centro de Salud de Lesaka. Tras la valoración se decide si precisa tratamiento (semanal), si sólo precisa un seguimiento (trimestral) o si el control ha de ser pediátrico.
Centro de Salud de Vera. Navarra.

Aceptado para su publicación el 3 de enero de 2006.

\section{Correspondencia:}

Belén Compains Beaumont

Centro de Salud

31780 Bera/Vera de Bidasoa

(Navarra) 
El tratamiento semanal puede ser de una a dos sesiones semanales y se llevan a cabo en el Centro de Salud de Lesaka y actualmente lo hace ANFAS a través de un convenio de colaboración con el Departamento de Bienestar Social.

- Niños de tres a seis años. El proceso depende del Departamento de Educación. Tras la detección, la tutora avisa a la orientadora, que será la que se encargue de solicitar una valoración y posterior tratamiento al CREENA (Centro de Recursos de Educación Especial de Navarra).

ANFAS oferta también de forma extraescolar el servicio de tres a seis años, pero esta prestación no es gratuita.

Desde que se implantó el servicio en octubre de 2003 , son 18 los niños que han llegado a ser atendidos. Tres fueron valorados previamente al proceso de implantación. De los 15 restantes, 5 se decidió que sólo acudirían a revisiones y el resto acudió también a tratamiento. Se produjeron dos abandonos, uno por familia poco constante y el otro porque se le ofertó atención temprana a partir de los tres años con ANFAS, no la aceptó.

La principal causa de derivación han sido retrasos madurativos generalizados, en algún caso en áreas específicas e incluso retrasos de origen social.

A pesar de que la mayoría de los niños estaban escolarizados, sobre todo a partir de los dos años, el tratamiento se ha realizado fuera del horario escolar aunque coordinados con el centro escolar.

Aparte de estos 18 niños que fueron derivados, hemos seguido en consulta de pediatría a otros tantos en un programa de riesgo de alteraciones de desarrollo. De éstos tres no aceptaron la derivación.

Las altas se producen en el momento de la escolarización en la etapa tres-seis años. El centro base emite un informe de cada niño que entrega a los padres y al orientador del centro correspondiente. El paso de la etapa tres-seis años a la siguiente, no requiere de una valoración especial, hasta ahora.
La valoración tras un año de funcionamiento ha sido muy positiva ya que cuando los niños se escolarizan ya están detectados los problemas más serios y ya se ha iniciado el proceso que garantice su adecuada integración. Existe además la posibilidad de complementar los recursos que el Departamento de Educación oferta con los que oferta ANFAS.

Se inicia un proceso de coordinación entre centro de salud/servicios sociales/ Departamento de Educación que persistirá durante toda la escolarización obligatoria. No obstante, sigue habiendo grandes lagunas que dificultan que este proceso se cumpla correctamente.

En la etapa 0-3 años está bastante bien establecido el circuito de detección derivación, sin embargo, en la coordinación no están establecidos los circuitos y los pediatras dependemos de llamadas por teléfono e interconsultas improvisadas entre niño y niño.

La etapa tres-seis años empeora, ya que además de esto, si un niño es detectado después de los tres años resulta difícil acceder a una valoración específica. El circuito en ocasiones no pasa de la valoración de la maestra y la orientadora tras unas observaciones y raramente antes de los 4 años. Según el compromiso adquirido sería un equipo de profesionales el que debería valorar al niño. Tampoco manejamos los mismos criterios de actuación. Mientras que los profesionales de salud proponemos un tratamiento individualizado más el tratamiento de apoyo al grupo, el Departamento de Educación raramente acepta un tratamiento individualizado antes de los cinco años.

Por otra parte, al menos en nuestros colegios la queja de todos los orientadores es la falta de recursos para atender correctamente a estos niños.

Reiteramos nuestra satisfacción por la implantación de este servicio en la zona. Estamos convencidos de que ha supuesto una mejora en la atención de los niños de Bortziriak y esperamos que esto repercuta en una mejora de su calidad de vida. Seguiremos trabajando para mejorar aspectos como la coordinación y la valoración en la etapa tres-seis años. 